\title{
INDUSTRIAL (B2B) MARKETING OF GLASS COMPANIES: MOBILE APPLICATIONS AS A SALES PROMOTION TOOL
}

\author{
Maxim Koldyshev ${ }^{1}$
}

\begin{abstract}
The purpose of the paper is a qualitative analysis of mobile applications as a sales promotion tool in industrial (B2B) marketing of glass companies. Industrial marketing of the glass industry is poorly studied in terms of digital technology development and integration as well as mobile applications as tools for digital marketing communications. B2B companies' digitalization is at the initial stage. Methodology. This research builds on the concepts of digital B2B marketing, the digitization capability of B2B companies, customer relationship building, and customer focus. The research methodology is based on the case study of $A B C$ company and the content analysis of information available on the $A B C$ 's website in the public domain. A content analysis was conducted of the patent for a method for determining the coated glass coating type using an application and a light source. Results demonstrate problems related to digital marketing concepts integration, customer focus, and customer relations formation. The results show an active digital strategy use for the company's business growth through software development and integration of end product interactive visualization tools. As a result, additional business value is formed: 1) end customer company focus; 2) product knowledge development and B2B services personalization; 3) manufacturers transfer some sales and communication functions to their customers, which solves the problem of staff rotation in the sales subsystem; 4) the application becomes a tool for customer behaviour analysis. Mobile applications complement any traditional product promotion channels. The main domestic industrial market challenge is the poor rate of readiness for digital changes: applications become an effective marketing communication tool only when customers use them. Practical implications. Companies in different industries can use the results to understand real issues of applications integration in marketing strategy and communication. These problems include the digital unpreparedness of the Russian domestic market to accept new technological solutions. Value/originality. This research proves that mobile applications increase sales and is effective if company personnel, end users and B2B customers actively use them. Applications complement traditional B2B marketing channels.
\end{abstract}

Key words: industrial (B2B) marketing, mobile applications, sales promotion tools, digital marketing communications.

JEL Classification: M31, M21, L63

\section{Introduction}

The Russian glass industry is characterized by the manufacturers producing the same type of product and promoting it with added value due to additional features. For example, companies produce architectural glass with solar control, energy-efficient coatings that, besides other things, add colour to the glass. The upward trend in manufacturing energy-efficient products provides a competitive advantage for manufacturers. Another important upward trend is business digitization, including the development of mobile and web applications for visualizing product appearance (Wali, Uduma \& Wright, 2016), the use of configurators that calculate lighting and thermal characteristics, assistant applications for step-by-step selection of the glass type, etc. Such technological solutions solve the problem of informing consumers about the product properties, the problem of maintaining market share and ensuring income stability. Despite the digitization of B2B marketing in the glass industry, these trends are upward as end-users know little about the characteristics of glass products.

\footnotetext{
Corresponding author:

${ }^{1}$ Computer and Automated Systems Software Engineering, Russian Federation.

E-mail: koldyshev@gmail.com

ORCID: http://orcid.org/0000-0001-9283-558X

ResearcherID: AAW-7296-2020
} 
According to the 2017 Windows End Users Survey conducted by the marketing center O.K.N.A. Marketing (November 2017) in Russia, end users do not know anything about the types and properties of glass coatings. The Internet or Mobile Office are increasingly important buying channels, the popularity of the window manufacturers' websites is growing, while the search engines like Yandex and Google become major information sources for customers. The main criteria for end users in choosing windows are price and quality $(29.5 \%$ and $28.3 \%$, respectively); potential impact on heating savings $(3.3 \%$ of customers in 2017 ) and environmental friendliness $(2.1 \%$ of customers) are the least important buying reasons (O.K.N.A. Marketing, 2017). This indicates a low culture of consumption and informing customers about the characteristics of glass, which can provide additional value to companies in the glass industry and increase the loyalty level. Window consumers generally do not turn to sellers to get information about the properties of the specific glass coating, only the sellers of the product can provide this relevant information. In this case, various applications for visualizing innovative products and for explaining the properties of glass coatings to end users become additional and more effective communication channels. As a result, the customer loyalty level will increase, the company will be able to ensure its income stability.

In the context of integrating the concepts of "digitization capability" of B2B companies (Ritter \& Pedersen, 2020) as a way to increase product value and form relationships with customers (Harker \& Egan, 2006), orientation of B2B companies towards the end users of their customers, the study of applications as a tool to increase sales is especially relevant. Given the fact that B2B companies are more focused on the product rather than the customer, the buyer (Wali, Uduma \& Wright, 2016), it is important to study the use of applications for providing product specific information, building relationships with end customers, and promoting sales.

The research objective is a qualitative analysis of mobile applications as a sales promotion tool in industrial (B2B) marketing of glass companies.

\section{Literature review}

The scientific literature has little studied the impact of mobile applications on the sales of B2B companies. Despite the use of digital marketing by $\mathrm{B} 2 \mathrm{~B}$ companies and the digital revolution in business over the past twenty years (Herhausen et al., 2020), scientific literature lacks comprehensive research on the underlying issues (Pandey, Nayal \& Rathore, 2020). Herhausen et al. (2020) identify two major gaps in this regard: "the practice gap, which identifies the deficit between managers' 'current' practices and their 'ideal' digital marketing capabilities; and, the knowledge gap, which demonstrates a significant divide between the digital marketing transformations in industrial firms and the extant scholarly knowledge that underpins this". At the same time, digital marketing communications and sales volume management ensure the competitive sustainable development of organizations (Pandey, Nayal \& Rathore, 2020). Digital business models (technological innovations that affect financial performance) challenge traditional thinking and concepts in a B2B environment (Lin et al., 2020). This suggests the need to study digital marketing tools for $\mathrm{B} 2 \mathrm{~B}$ companies to increase and maintain sales, conceptualize new ideas for business development.

Ayman, Kaya \& Halim (2019) consider mobile applications as a way of interaction between buyers and sellers, as a tool of marketing communication strategy. Parkkinen \& Hoțoleanu (2017) conclude that technology as a communication tool increases consumer knowledge of the company's products, increasing their awareness. However, some technological solutions are part of digital marketing. In B2B, the sales cycle is long, multi-stakeholder driven, while digital tools and sales channels complement traditional ones (Veronica, Silvia \& Lavinia, 2018). Technological solutions provide the development of product knowledge and B2B sector services personalization (Wali, Uduma \& Wright, 2016), while they may not be sufficiently focused on end users. This results in a risk of growing costs for the development of applications that inform B2B customers about the product, but do not provide information to end users about the characteristics and properties of the product. That underlines that the true major goal of B2B companies could be solely profit driven mentality, and much less of the end customer satisfaction.

Feng et al. (2020) argue that mobile habits influence buying behaviour, intent: buyers who use communication apps are more likely to purchase a product. As the number of the Internet and mobile device users grows, companies are actively promoting their products online. 
Mobile targeting is being integrated into $\mathrm{B} 2 \mathrm{~B}$ marketing strategies. Mobile apps are an example of customer interaction (Wang, 2020). Mobile devices provide instant customer interaction and customer service, complementing traditional product promotion channels. Improvements in the targeted capabilities of mobile devices have driven progress in the use and development of mobile applications, and subsequently - in mobile commerce (Feng et al., 2020). "Mobile targeting in $\mathrm{B} 2 \mathrm{~B}$ markets involves connecting with the right business partners and, eventually, profitable consumers" (Feng et al., 2020). Applications complement other digital sales tools (Wang, 2020).

The use of mobile devices provides contextual information about customers, as well as opportunities to improve marketing strategies and targeted product promotion campaigns (Tong, Luo \& Xu, 2020). As product personalization becomes more and more important in the context of profitability, scientific literature covers personalized mobile marketing strategies (Tong, Luo \& Xu, 2020). Mobile applications are product personalization tools and thus open up new challenges for B2B digital marketing research.

\section{Materials and methods}

\subsection{Concept and design}

This research builds on the concepts of digital B2B marketing, the digitization capability of B2B companies (Ritter \& Pedersen, 2020), customer relationship building (Harker \& Egan, 2006), and customer focus (Hall, 2017), which implies the orientation of $\mathrm{B} 2 \mathrm{~B}$ companies towards the end users of their customers. Integrating these ideas into business is a way to increase sales and customer loyalty, create product value and develop a consumption culture. The integration concept tools are technological mobile applications that have been actively used by companies since 2000 (Hall, 2017).

The research design is qualitative, since the methods of content analysis of the website of $\mathrm{ABC}$ company (the company name was changed for confidentiality reasons) operating in the glass industry and the case study method were used. As the Internet is one of the main product promotion channels in the glass industry, website analysis can determine the effects of application use.

\subsection{Methods and data}

The research methodology is based on the case study of $\mathrm{ABC}$ company and the content analysis of information available on the ABC's website in the public domain. Besides, a content analysis was conducted of the patent for a method for determining the coated glass coating type using an application and a light source. The analysis of the patent allowed determining the stages of the application methodology.

\subsection{Research limitations}

The main research limitations were personal data protection and data privacy of $\mathrm{ABC}$ company, Russian float glass manufacturer. The patent and information posted on the company's website did not allow to fully quantify the effect of using a mobile application as a way to increase sales. In addition, there was no quantitative data for the glass industry to analyse dynamics, and publicly available company data to assess application effectiveness by studying sales dynamics.

\section{Results}

\subsection{Information about the company and technologies used to promote sales}

$\mathrm{ABC}$ is a manufacturer of float glass and sputtered glass for exterior use in residential and commercial buildings. The main feature of the glass companies is continuous glass production. The glass furnace cycle is approximately $15-20$ years. Regardless of the level of demand for glass, glass furnaces produce in average $500-1000$ tons of glass per day depending on its design. Long-term planning allows managing production and seasonality. Most of the products have a fairly stable demand: $80 \%$ of production volumes are consumed by $20 \%$ of customers and ensures the accuracy of demand forecasts. The industry uses statistical forecasting systems.

During the crisis periods, when the construction and automotive industries are suspended, glass manufacturers increase their stocks in warehouses, crush the glass into cullet and melt it again (the socalled cycling). Cycling is expensive, but compared to furnace cooldown, it is a more cost effective way to maintain operation.

The main product of $\mathrm{ABC}$ is float glass. This transparent sheet glass is produced by a large number of manufacturers, both large international (AGC, Guardian, Saint-Gobain, Pilkington, etc.) 
and regional (SalavatSteklo, Gomel Glass, etc.). Float glass has little difference from manufacturer to manufacturer and thus considered to be a commodity product. That is why, manufacturers promote float glass with added value (architectural glass with solar-protection coatings, energy-saving coatings that give colour to glass), including through mobile and web applications (appearance visualizers, configurators calculating lighting and thermal characteristics, assistant applications for step-by-step selection of the type of glass, etc.).

Since competition landscape on uncoated float glass is tight manufacturers are investing into fabrication lines in order to add additional properties to base glass:

- magnetron sputter coatings - for energy-saving (LowE) and solar control coatings application (for use in residential windows and commercial facades);

- wet coaters lines for mirror and painted glass production;

- laminated lines for safety and acoustic glass production;

- acid etching lines for use in interiors;

- ultra-thin (less than $2 \mathrm{~mm}$ ) glass, or thick (over 12 $\mathrm{mm}$ ), XXL Jumbo glass sizes (over 7-20 m long);

- and others.

The main problems of companies in the glass industry are the following:

- Low profitability of commodity products. Phonecia Glass, YugSteklo are examples of manufacturers' bankruptcies that have not provided competitive advantages, brand identification and have not expanded the range with more marginal products. An example of a competitive company is Guardian Glass, Ryazan (BusinessStat, 2019), which is driving growth by increasing production of energy-efficient glass. In the context of a fall in the domestic market, stagnation of the economy in 2014-2016, the introduction of new building codes and regulations, the sales growth of glass manufacturers will grow.

- Seasonality, which is an acute shortage of glass in the summer-autumn period, redundancy in the winter-spring period.

- Poor awareness of the end user about the glass properties and its role in overall window or facade performance. Glass takes around $80 \%$ of the window area, and it is hard to underestimate its impact on solar control and energy saving features of the window. A customer faces the need to install and replace windows only 1-2 times in his or her life. Consequently, the customer is not aware of innovations and new features in glazing area. Therefore, the main task of manufacturers and distributors is to inform customers. The main promotion channels are word of mouth, opinion leaders, the Internet, bloggers, TV re-modelling shows.

- Complicated supply chain to the end consumer. As a producer of raw materials, glass producers should work with window manufacturers and distributors of the final product to the end users, considering the peculiarities of $\mathrm{B} 2 \mathrm{~B}$ and $\mathrm{B} 2 \mathrm{C}$ sales. High employee turnover at points of sale leads to difficulties in maintaining the level of competence of the window sellers (constant trainings, conferences, training videos for salesmen are very costly ways of developing competencies). This leads to the fact that salesmen at B2C points of sale do not always inform end buyers about the glass properties.

- ABC's indirect competitors are manufacturers of bricks and other no transparent wall. The efforts of architects, designers, developers to popularize large window openings, glass walls provide the company with a demand, instil a culture of glass consumption. The lack of regulations requiring the use of energysaving glass in windows in several countries is an advantage for manufacturers of bricks, foam blocks and other products.

\subsection{Digital online resources for sales promotion}

The before mentioned operational problems, mainly related to marketing and sales, led $A B C$ to the need to develop digital tools for promoting sales. These tools include:

1. Software for system analysis of product (float glass) and glazing systems. The online resource Glass Analytics - is available on the $\mathrm{ABC}$ website and offers users a choice of programs for obtaining engineering calculations of technical characteristics. This allows visualizing the advantages of using sputtered glass for glazing facades.

2. Performance Calculator or Online Configurator software (BIM Generator software), which simplifies the selection of the optimal glass and is easy to use thanks to a simple user interface. The configurator allows calculating the thermal and lighting properties of glazing (for example, single glass without coating or complex combinations of base glass, various coatings and intermediate layers). The configurator allows to analyse the thermal and lighting properties of different options, 
create a visual report that compares the properties of glazing of different categories in the most convenient form for the buyer. The tool contains highly detailed content and filters by parameters based on the client preferences. The set criteria or parameters provide control over the size of the spacer, the type of glass fixing in the glass unit.

3. The ABC Glass Visualizer software or realtime visualizer allows to generate photorealistic images of glazing from the inside and outside of the building selected by the customer. The resource allows the user to evaluate the aesthetic component of different glass types.

4. Mobile stands for demonstrating the energy saving features of insulating glass units, which allows the buyer to experience interaction with the product.

Thus, the ABC's website contains online resources for product analysis, glazing systems, a software for calculating the thermal and lighting properties of glazing, generating photorealistic images of glazing, and calculating the optical and thermal characteristics of glass units.

\subsection{Mobile applications as a way of promoting sales}

A separate tool in the communication marketing strategy is an interactive tool for selecting the optimal glass unit formula for a customer in the form of the $A B C$ Glass Expert mobile application for iOS and Android. The application has a number of features: user analytics, loyal user identification, video tutorials, and business process reports. The mobile application shows the user the stages of selecting the optimal solution by determining the cardinal position of the window, the colour shade and the noise insulation level. The application is aimed at Window Sales Managers and Measurers. In the administrative panel, administrators of regional levels of $A B C$ have the ability to manage content in the client application.

The main implementation problems of the application development project were to ensure the offline operation of the application in the absence of an Internet connection, localization of the application around the world and the availability of the application to any user, understanding their specific user journeys.

An important stage in the integration of the $A B C$ Coating Recognition application was the patenting of the method for determining the coated glass type using the application and the light source. The patent was registered in Russia and the USA. The method for determining a glass unit is as follows:

1. The user takes a light source and brings it to the glass unit.

2. Takes a photograph with an app of the original flame with its reflections from each glass surfaces in the glass unit.

3. The system analyses the deviation in colour of the body of flame from each of the surfaces and compares it with the application's spectral data library.

4. Based on the comparison, an assumption is made as to the type of coating probability, and the surface it is located at within a glass unit.

Analysis of the application's functionality allowed identifying potential scope of the application:

1. The end user can determine the type of glass coating (energy-saving or solar control).

2. Installation teams can confirm the correct glass unit orientation within the window.

3. Architects, inspection and supervisory authorities can determine the type of glass installed on the facade of the building in case of documentation loss.

\section{Discussion}

The results demonstrate the use of ABC's proactive digital business growth strategy through software development and the integration of interactive technology tools into the work of their staff. This confirms the findings of other studies in this area: "the use of electronic means of cooperation between the companies continues to grow in strength and dynamics" (Pawłowski \& Pastuszak, 2017). Software and applications allow to create added value in the form of the final product visualization. $\mathrm{B} 2 \mathrm{~B}$ marketing is becoming more consumer-oriented through mobile applications. In comparison with the results of Wali, Uduma \& Wright (2016), this study allows to conclude that technological solutions in the form of applications not only provide product knowledge, personalization of services in the $\mathrm{B} 2 \mathrm{~B}$ sector, but are targeted at end users. At the same time, $A B C$ develops software both for internal and external use (end users and customers). Thus, $A B C$ as a supplier of float glass partially transfers a number of sales and customer information functions to its customers, and solves the problem of employee turnover in the sales subsystem. According to the findings, Pawłowski \& Pastuszak (2017) "We observe growing "self-service with everything"; 
providers will pass on to buyers and systems, most actions which they can perform by themselves." As the number of mobile device users will increase in the future, the trend towards self-service in the glass industry will gradually increase. Companies, which are technologically ready for such digital transformations, will have a competitive advantage in the marketplace.

The ABC mobile application is also a tool for analysing end user data, forming knowledge about customers and their behaviour. This leads to knowledge of the market as a whole and allows for more detailed segmenting of customers. Similar conclusions were made by Paschen, Kietzmann \& Kietzmann (2019): technologies based on artificial intelligence and big data are influencing the transformation of marketing in the B2B segment in terms of knowledge management about customer behaviour.

The findings of this study correlate with the results of Feng et al., (2019) on digital augmentation of traditional marketing channels based on content marketing and technology solutions. This allows to instantly interact with customers and end users, identify purchase problems, and solve the problem of a long sales chain. "Branded app adoption and uses increase customers' website interactions... increase customers' spending and promotional responses" (Wang, 2020).

As a result of the portability, accessibility to owners and multifunctionality of mobile devices, multidimensional data is collected on the activities of consumers who use applications on their mobile phones that can effectively describe their habits (Feng et al., 2019). Thus, ABC should pay more attention to mobile customer data to gain insight into customer behaviour and develop new products. Mobile phone big data will enable B2B glass manufacturers to better understand not only their customers, but also their business partners, competitors and players in the B2B markets in general. Ultimately, this will lead to better customer interaction strategies and increased sales.

Digitization through the integration of mobile applications also carries the risk of resource scarcity and accelerated sales decline. This is due to the peculiarities of the Russian glass industry market and consumer behaviour in this market. The domestic market is not entirely ready for such changes, the mobile application is available for use only by the company's employees, and the end customer data is limited by the 2017 survey data.
A mobile application can be an effective tool for transferring the functions of marketers and sales managers if such a tool is actively used by buyers. Consumer survey data from the 2017 Windows End User Opinion Survey show low mobile application usage and an emphasis on price as a key purchase criterion. This suggests that in the next five to ten years the mobile application may almost not be used by buyers of the Russian market. This leads to both costs and lack of effect from digitization. As Deryabina \& Trubnikova (2019) state, "decreasing the human field resources in parallel before reaching the desired economic effects, can bring the companies to resources gap and as a consequence to acceleration of decrease of sales". At the same time, ABC Company has problems with a long sales chain and high turnover of personnel at the end points of sales. A mobile application is a way to solve these problems and, at the same time, by informing consumers about the properties of the product, and building loyalty.

\section{Conclusion}

This research leads to three main findings. Firstly, mobile applications as a tool to increase sales are effective if they are actively used by company personnel, end users and B2B customers. The penetration rate of the number of users depends on digital skills and technological readiness of both companies in the B2B segment and customers. Secondly, the active use of the company's digital business growth strategy and digital marketing communications leads to the formation of additional values: 1) development of customer-oriented business; 2) development of knowledge about the company's products among external and internal stakeholders; 3) personalization of products in the $\mathrm{B} 2 \mathrm{~B}$ segment; 4) solving the employee turnover problem and employee incompetence, primarily sales managers, by informing buyers about the properties of the product through interactive technologies; 5) the possibility of accurate detailed analysis of data about customers (B2B) and end users, their behaviour and the mechanism of making a purchase decision. Third, applications complement traditional B2B marketing channels. This is due to a number of problems, including the digital unpreparedness of the Russian domestic market to accept new technological solutions. As a consequence, the integration of applications into the sales system leads to additional costs for 
the company while providing effects in the long run. At the same time, the company has a problem of insufficient competence of sales managers due to employee turnover. This does not allow to instantly solve the problem of a long sales chain and, with the help of applications, reduce the period of informing the end users about the main advantages of the products. Since the active use of applications by stakeholders can be expected in five to seven years, the above problems can be solved by continuing active digital marketing communication.

\section{References:}

Ayman, U., Kaya, A. K., \& Halim, I. (2019). Mobile App Marketing Communication for B2B and B2C: Ingoes as a Case Study. In Consumer Behavior and Marketing. IntechOpen. doi: 10.5772/intechopen.85008 BusinessStat (2019). Analiz ryinka listovogo stekla v Rossii v 2014-2018 gg, prognoz na 2019-2023 gg. Available: https://marketing.rbc.ru/research/42399/

Boyd, D. E., \& Koles, B. (2019). Virtual reality and its impact on B2B marketing: A value-in-use perspective. Journal of Business Research, vol. 100, pp. 590-598.

Deryabina, G., \& Trubnikova, N. (2019). Digital B2B Communications: Economic and Marketing Effects. Institute of Scientific Communications Conference: 866-875. Springer, Cham.

Feng, X., Li, Y., Lin, X., \& Ning, Y. (2020). Mobile targeting in industrial marketing: Connecting with the right businesses. Industrial Marketing Management, vol. 86, pp. 65-76. doi: 10.1016 ) j.indmarman.2019.06.007

Hall, S. (2017). Innovative B2B marketing: new models, processes and theory. Kogan Page Publishers.

Harker, M. J., \& Egan, J. (2006). The past, present and future of relationship marketing. Journal of marketing management, vol. 22(1-2), pp. 215-242.

Herhausen, D., Miočević, D., Morgan, R. E., \& Kleijnen, M. H. (2020). The digital marketing capabilities gap. Industrial Marketing Management, vol. 90, pp. 276-290. doi: 10.1016/j.indmarman.2020.07.022

Lin, W. L., Yip, N., Ho, J. A., \& Sambasivan, M. (2020). The adoption of technological innovations in a B2B context and its impact on firm performance: An ethical leadership perspective. Industrial Marketing Management, vol. 89, pp. 61-71. doi: 10.1016/j.indmarman.2019.12.009

Pandey, N., Nayal, P., \& Rathore, A. S. (2020). Digital marketing for B2B organizations: structured literature review and future research directions. Journal of Business \& Industrial Marketing, vol. 35(7), pp. 1191-1204. doi: 10.1108/JBIM-06-2019-0283

Parkkinen, T., \& Hoțoleanu, M. (2017). Inbound Marketing Strategy: Content Marketing and Blogging: Case: Cloud-based mobile application. Available at: http://urn.fi/URN:NBN:fi:amk-2018092015277

Paschen, J., Kietzmann, J., \& Kietzmann, T. C. (2019). Artificial intelligence (AI) and its implications for market knowledge in B2B marketing. Journal of Business \& Industrial Marketing, vol. 34(7), pp. 1410-1419. doi: 10.1108/JBIM-10-2018-0295

Pawłowski, M., \& Pastuszak, Z. (2017). B2B customers buying behavior. International Journal of Synergy and Research, vol. 5, p. 19.

Ritter, T., \& Pedersen, C. L. (2020). Digitization capability and the digitalization of business models in business-to-business firms: Past, present, and future. Industrial Marketing Management, vol. 86, pp. 180-190.

Rizomyliotis, I., Konstantoulaki, K., \& Kostopoulos, I. (2017). What Is Next for Business-to-Business Marketing Communication? Business-to-Business Marketing Communications: 79-90. Palgrave Macmillan, Cham.

The American Institute of Architects (2019). The Architect's Journey to Specification 2019. Available at: https://www.aia.org/resources/85766-the-architects-journey-to-specification: 46

Tong, S., Luo, X., \& Xu, B. (2020). Personalized mobile marketing strategies. Journal of the Academy of Marketing Science, vol. 48(1), pp. 64-78.

Veronica, P., Silvia, M., \& Lavinia, P. A. (2018). Traditional versus online marketing for B2B organizations: Where the line blurs. Ovidius University Annals, Economic Sciences Series, vol. 18(1), pp. 382-387.

Wali, A. F., Uduma, I. A., \& Wright, L. T. (2016). Customer relationship management (CRM) experiences of Business-to-Business (B2B) marketing firms: A qualitative study. Cogent Business \& Management, 3(1): 1183555. doi: 10.1080/23311975.2016.1183555

Wang, R. J. H. (2020). Branded mobile application adoption and customer engagement behavior. Computers in Human Behavior, 106: 106245. doi: 10.1016/j.chb.2020.106245

O.K.N.A. Marketing (2017). Issledovanie mnenii konechnykh potrebitelei PVKh-okon. 